\title{
Role of Corticosteroids in Rhabdomyolysis
}

\author{
Shivam Krishna Patel ${ }^{1}$, Sandeep Anand Padala ${ }^{*}$, Azeem Mohammed ${ }^{2}$ and Rajan Kapoor ${ }^{2}$ \\ ${ }^{1}$ Department of Medicine, Nephrology, Augusta University, Medical College of Georgia, 1120, 15th St, Augusta, GA 30912, USA \\ ${ }^{2}$ Department of Medicine, Nephrology, Augusta University Medical Center, Medical College of Georgia, 1120, 15th St, Augusta, GA 30912, USA
}

${ }^{*}$ Corresponding author: Sandeep Anand Padala, MD, Department of Medicine, Nephrology, Augusta University, Medical College of Georgia, 1120 15th St, Augusta, GA 30912, USA; TEL: (516)673-6675; EMAIL: spadala@augusta.edu

Received: November 13, 2019; Accepted: November 26, 2019; Published: December 01, 2019

\section{Background}

Rhabdomyolysis is a medical condition that involves rapid breakdown of injured skeletal muscle, resulting in the leakage of muscle contents into the circulation. The most common causes of rhabdomyolysis include trauma, muscle overexertion, alcohol abuse, and the use of certain medications and illicit drugs. The goal of the treatment is usually to maintain adequate volume repletion to prevent renal failure and metabolic abnormalities. Hemodialysis is an alternative therapy to prevent renal failure when there is no response to aggressive intravenous hydration. We present a case of severe rhabdomyolysis that was refractory to the current standard of care and showed dramatic improvement with corticosteroids.

\section{Case Report}

We present a case of a 52-year-old African American male who presented to the emergency department from an outside hospital for acute hypoxemic respiratory failure requiring intubation and septic shock. On presentation, his vital signs were as follows: temperature, $39.2^{\circ} \mathrm{C}$; heart rate, 114 beats $/ \mathrm{min}$; respiratory rate, 48 breaths/ min; blood pressure, 122/74 mm Hg on two vasopressors; oxygen saturation, $98 \%$ on pressure-regulated volume control with $\mathrm{FiO}_{2}$ of $80 \%$; BMI, 51.9. Of note, his creatine kinase (CK) upon admission was $231,000 \mathrm{U} / \mathrm{L}$. Before the transfer; the patient received about 2 liters of intravenous hydration. Physical examination revealed a morbidly obese adult male with an erythematous and swollen right lower extremity with palpable posterior tibial and dorsalis pedispulses without any evidence of crepitus, pustular drainage, or a central punctum. The right lower extremity was warm to the touch in comparison to the left lower extremity. Findings on physical examination were otherwise unremarkable. We were unable to obtain any of his medical or medication history or any of his prior records. He was admitted to the medical intensive care unit and laboratory results were obtained, as shown in Table 1. ICU Day 5 and Day 11 are provided to show changes over the time of his admission. In the setting of rhabdomyolysis, the working diagnosis was septic shock secondary to right lower extremity cellulitis. Empiric intravenous vancomycin, cefepime, and metronidazole were initiated after blood cultures were obtained. Imaging studies ruled out any evidence of deep vein thrombosis in the lower extremities.

On Day 1 of admission into the ICU, Nephrology was consulted for an uric renal failure and metabolic abnormalities despite aggressive intravenous hydration and vasopressors support. Since a urine analysis and urine toxicology could not be performed, the acute kidney injury (AKI) waspresumed to be secondary to rhabdomyolysis and septic shock. He was originally started on hemodialysis on Day 1, but given the worsening electrolyte and acid derangements, renal replacement therapy (RRT) with intermittent hemodialysis followed by continuous veno-venous hemodiafiltration (CVVHDF) was initiated on Day 2. Despite aggressive therapy, the CK levels increased to $1,006,167$ $\mathrm{U} / \mathrm{L}$ on Day 3, prompting a surgical consult and necrotizing fasciitis was ruled out. Given the severity of rhabdomyolysis, rheumatology was consulted and the workup including double strandeddeoxyribonucleic acid (ds-DNA), antibodies against La/SSB and Ro/SSA, Jo 1 and cyclic-citrullinated peptide (CCP) were negative. With CK levels over one million, we recommended intravenous corticosteroids, but the treatment was initiated onDay 4 when the CK levels dropped to 652,798 U/L. A 3-day pulse dose therapy of 1000 $\mathrm{mg}$ of intravenous Methylprednisolone was then initiated on Day 4.After corticosteroid treatment, the patient's labs continued to show a significant decline in CK levels, as seen in Figure 1. A proximal muscle biopsy was performed on Day 6, which was also the day the patient received his final dose of IV Methyl prednisolone. The final pathology report stated that there was extensive acute rhabdomyolysis with minimal macrophage infiltration suggesting minimal inflammatory, reactive or regenerative activity that may have been due to the effect of the corticosteroids.CK levels trended down to 10,005 U/L over the course of six days. Despite the improvement of the rhabdomyolysis and ongoing CRRT throughout the course of his ICU stay, the patient clinically worsened secondary to methicillin-resistant Staphylococcus aureus (MRSA) pneumonia and Candida albicans bacteremia. The patient ultimately died secondary to multisystem organ failure.

\section{Discussion}

Rhabdomyolysis is characterized by skeletal muscle necrosis and dissolution of intracellular muscle components leading to the release of myoglobin, electrolytes, and proteins into the circulation [1].It can be multifactorial in etiology including trauma, drugs, muscle hypoxia, exercise, genetic and metabolic disorders, electrolyte abnormalities, infections and idiopathic[1-3]. Also, any defects in muscle metabolism may present with recurrent episodes of rhabdomyolysis [4-6]. In the United States, the incidence of AKI as a complication of rhabdomyolysis accounts for 7 to $10 \%$ of all the AKI cases [6, 7]. The pathogenesis of rhabdomyolysis involvesthe depletion of adenosine 
triphosphate (ATP) within the myocyte, causingan unregulated increase in intracellular calcium [8,9]. Under normal conditions, the sarcoplasmic calcium is strictly regulated, and it maintains low levels of calcium when the muscle is at rest and allows the increase that is necessary for actin-myosin binding and muscle contraction. ATP depletion impairs the function of these pumps, resulting in a persistent increase in sarcoplasmic calcium leading to persistent contraction which further depletes ATP. This leads to the eventual destruction of myofibrillar, cytoskeletal, and membrane proteins causing large amounts of myoglobin and CK release[1].Myoglobin is a heme-containing protein measuring about $17.8-\mathrm{kDa}$ that is freely filtered by the glomerulus and metabolized by tubular epithelial cells. It can be seen in the urine only when the renal threshold of 0.5 to 1.5 $\mathrm{mg} / \mathrm{dL}$ of myoglobin is exceeded and can present with reddish-brown colored urine when the serum myoglobin levels reach $100 \mathrm{mg} / \mathrm{dL}$ [10]. Myoglobinuria can be picked up on the urinary dipstick as positive for blood in the absence of red blood cells. Though the serum myoglobin levels peaks before the serum creatinine kinase, the serum myoglobin has a rapid and unpredictable metabolism via the kidney and the liver or spleen [11].

Depending upon the extent of the muscle damage, the clinical presentation can vary. Greater than $50 \%$ of patients do not present with the classic triad of myalgias, weakness and tea-colored urine [10]. Limb weakness, swelling, myalgias, and gross pigmenturia without hematuria are commonly seen in cases with severe muscle necrosis. The complications of rhabdomyolysis include intravascular volume depletion, renal failure, arrhythmias due to electrolyte abnormalities, compartment syndrome, acidosis, and disseminated intravascular coagulation. Patients admitted to the intensive care unit have a concomitant mortality rate of $22 \%$, and if there is an associated kidney insult, then the mortality rate can be as high as 59\% [6]. Under normal conditions at resting stage, intracellularly there are low concentrations of sodium and calcium and higher potassium concentrations which are tightly controlled with the sodium-potassium and sodium-calcium exchangers. Whenever there is a muscle injury or ATP depletion, the functioning of this channel is compromised leading to excessive calcium and sodium within the cells and extravasation of potassium into the bloodstream. High intracellular sodium leads to water influx, cell swelling, and intravascular volume depletion [12]. Fluid sequestration within damaged muscle causes intravascular volume depletion resulting in activation of the renin-angiotensin-aldosterone system and sympathetic nervous system, thus precipitating the pre-existing renal injury [12]. First-line treatment for rhabdomyolysis is aggressive fluid resuscitation to maintain an adequate urine output of at least 200 to $300 \mathrm{~mL}$ per hour to prevent the accumulation of intracellular toxins in circulation which can subsequently lead to AKI. Diuretics are recommended only when there are signs of fluid overload. Dialysis becomes necessary when the patient has unremitting metabolic abnormalities inspite of conservative management. However, dialysis is not a valid treatment option for rhabdomyolysis because myoglobin cannot be removed effectively due to the size of the protein. Dialysis is usually recommended by renal indications, such as acid/base disorders, electrolyte disturbances, volume overload, and uremia [13]. In the case of our patient, dialysis was initiated because he was an uric and had metabolic disturbances. Treatment becomes significantly challenging if patients fail to show improvement to dialysis and the cause of the insult remains unknown.

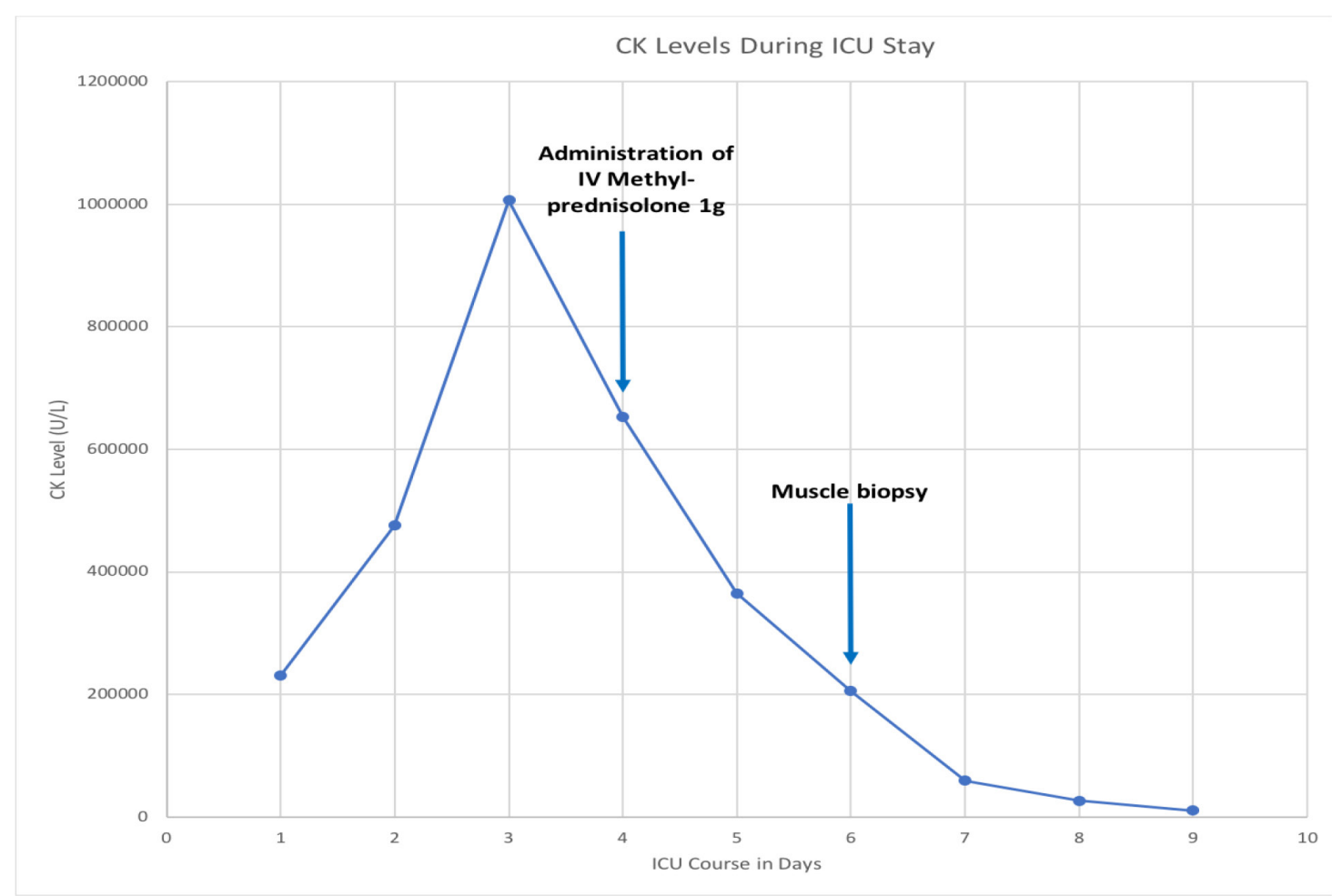

Figure 1. Graph showing the response of CK levels after administration of IV Methyl prednisolone 1000mg. 
Table 1. Laboratory Data.

\begin{tabular}{|c|c|c|c|}
\hline & Admission & ICU Day 5 & ICU Day 11 \\
\hline White blood count & 22.7 thousand $/ \mathrm{mm}^{3}$ & 37.6 thousand $/ \mathrm{mm}^{3}$ & 64.9 thousand $/ \mathrm{mm}^{3}$ \\
\hline Red blood count & $5.61 \mathrm{million} / \mathrm{mm}^{3}$ & 4.24 million $/ \mathrm{mm}^{3}$ & $3.12 \mathrm{million} / \mathrm{mm}^{3}$ \\
\hline Hemoglobin & $14.6 \mathrm{~g} / \mathrm{dL}$ & $11.1 \mathrm{~g} / \mathrm{dL}$ & $8.1 \mathrm{~g} / \mathrm{dL}$ \\
\hline Platelet & 246 thousand $/ \mathrm{mm}^{3}$ & 224 thousand $/ \mathrm{mm}^{3}$ & 157 thousand $/ \mathrm{mm}^{3}$ \\
\hline Sodium & $133 \mathrm{mEq} / \mathrm{L}$ & $132 \mathrm{mEq} / \mathrm{L}$ & $136 \mathrm{mEq} / \mathrm{L}$ \\
\hline Potassium & $5.3 \mathrm{mEq} / \mathrm{L}$ & $4.5 \mathrm{mEq} / \mathrm{L}$ & $5.9 \mathrm{mEq} / \mathrm{L}$ \\
\hline Bicarbonate & $31 \mathrm{mEq} / \mathrm{L}$ & $21 \mathrm{mEq} / \mathrm{L}$ & $8 \mathrm{mEq} / \mathrm{L}$ \\
\hline Blood Urea Nitrogen & $41 \mathrm{mg} / \mathrm{dL}$ & $49 \mathrm{mg} / \mathrm{dL}$ & $20 \mathrm{mg} / \mathrm{dL}$ \\
\hline Creatinine & $6.42 \mathrm{mg} / \mathrm{dL}$ & $3.44 \mathrm{mg} / \mathrm{dL}$ & $1.65 \mathrm{mg} / \mathrm{dL}$ \\
\hline Glucose & $217 \mathrm{mg} / \mathrm{dL}$ & $265 \mathrm{mg} / \mathrm{dL}$ & $235 \mathrm{mg} / \mathrm{dL}$ \\
\hline Calcium & $7.0 \mathrm{mg} / \mathrm{dL}$ & $7.0 \mathrm{mg} / \mathrm{dL}$ & $7.0 \mathrm{mg} / \mathrm{dL}$ \\
\hline Total Protein & $7.4 \mathrm{~g} / \mathrm{dL}$ & $8.0 \mathrm{~g} / \mathrm{dL}$ & $6.0 \mathrm{~g} / \mathrm{dL}$ \\
\hline Total Bilirubin & $0.7 \mathrm{mg} / \mathrm{dL}$ & $1.3 \mathrm{mg} / \mathrm{dL}$ & $0.8 \mathrm{mg} / \mathrm{dL}$ \\
\hline Phosphorus & $13 \mathrm{mg} / \mathrm{dL}$ & $5.6 \mathrm{mg} / \mathrm{dL}$ & $7.7 \mathrm{mg} / \mathrm{dL}$ \\
\hline Blood Natriuretic Peptide & $21 \mathrm{pg} / \mathrm{mL}$ & - & - \\
\hline Creatine Kinase & $231000 \mathrm{U} / \mathrm{L}$ & $181412 \mathrm{U} / \mathrm{L}$ & $4638 \mathrm{U} / \mathrm{L}$ \\
\hline Lactic Acid & $7.9 \mathrm{mmol} / \mathrm{L}$ & $2.8 \mathrm{mmol} / \mathrm{L}$ & $5.7 \mathrm{mmol} / \mathrm{L}$ \\
\hline Magnesium & $2.6 \mathrm{mg} / \mathrm{dL}$ & $2.2 \mathrm{mg} / \mathrm{dL}$ & $2.3 \mathrm{mg} / \mathrm{dL}$ \\
\hline Ammonia & 66 umol/L (High) & - & - \\
\hline
\end{tabular}

Literature review shows that there are only four cases in which intravenous corticosteroid use is administered in the treatment of rhabdomyolysis [13-16].The rationale for steroids in these cases is that the muscle necrosis in rhabdomyolysis has a significant inflammatory element, which is supported by the successful reduction of CK levels after the administration of IV Methylprednisolone. However, none of the above-mentioned case reports had such high levels of CK. In our case, the laboratory values showed continued improvement after beginning the three-day pulse dose therapy, with levels declining from $652,798 \mathrm{U} / \mathrm{L}$ to $58,947 \mathrm{U} / \mathrm{L}$. We cannot exclude the possibility that this patient's recovery status was predominantly secondary to the natural history of the disease as improvement was seen prior to commencing steroids. Nonetheless, the significant improvement in CK levels and a biopsy revealing minimal inflammation suggest the pharmacologic effect of the corticosteroids exhibited a noteworthy component. Rhabdomyolysis muscle biopsies show inflammation and neutrophilic infiltration with muscle necrosis due to a pathologic interaction between actin and myosin. Histochemical analysis is done if a genetic myopathy is suspected. Generally, muscle biopsies can help differentiate acquired from inherited causes by the use of histochemistry, but the pathological findings are similar in all cases that are acquired $[17,18]$. When comparing our patient's muscle biopsy to one depicting an acute inflammatory state, our patient showed significantly less inflammation. 


\section{Conclusion}

Rhabdomyolysis is a medical condition that involves the breakdown of injured muscle leading to electrolyte abnormalities including hyperkalemia, hypocalcemia, hyperphosphatemia, hyperuricemia, acute renal failure, compartment syndrome, disseminated intravascular coagulation and or death.Despite multiple causes of rhabdomyolysis, there are limited treatment options for patients who do not show clinical improvementwith aggressive intravenous fluid hydration and dialysis. Short-term administration of high-dose corticosteroids may decrease the inflammatory reaction of rhabdomyolysis and lead to improvement in the patients CK levels. Further studies are needed to identify the most appropriate duration and the time to administer the steroids for the greatest success rate.

\section{References}

1. Xavier B, Esteban P, Josep G (2009) Rhabdomyolysis and Acute Kidney Injury. $N$ Engl J Med 361: 62-72.

2. Chavez LO, Leon M, Einav S, Varon J (2016) Beyond muscle destruction: a systematic review of rhabdomyolysis for clinical practice. Crit Care 20: 135. [crossref]

3. Nance JR, Mammen AL (2015) Diagnostic evaluation of rhabdomyolysis. Muscle Nerve 51: 793-810. [crossref]

4. Tein I, DiMauro S, Rowland LP (1992) Myoglobinuria. In: Rowland LP, DiMauro S, (eds.). Myopathies. Handbook of clinical neurology. Vol. 62. Amsterdam: Elsevier Science Publishers Pg No: 553-593.

5. Allison RC, Bedsole DL (2003) The other medical causes of rhabdomyolysis. Am J Med Sci 326: 79-88. [crossref]

6. Bagley WH, Yang H, Shah KH (2007) Rhabdomyolysis. Intern Emerg Med 2: 210-218.

7. Holt SG, Moore KP (2001) Pathogenesis and treatment of renal dysfunction in rhabdomyolysis. Intensive Care Med 27: 803-811. [crossref]

8. Giannoglou GD, Chatzizisis YS, Misirli G (2007) The syndrome of rhabdomyolysis: pathophysiology and diagnosis. Eur J Intern Med 18: 90-100. [crossref]

9. Wrogemann K, Pena SD (1976) Mitochondrial calcium overload: a general mechanism for cell-necrosis in muscle diseases. Lancet 1: 672-674. [crossref]

10. Knochel JP (1982) Rhabdomyolysis and myoglobinuria. Annu Rev Med 33: 435 443. [crossref]

11. Mikkelsen TS, Toft P (2005) Prognostic value, kinetics and effect of CVVHDF on serum of the myoglobin and creatine kinase in critically ill patients with rhabdomyolysis. ActaAnaesthesiol Scand 49: 859-864. [crossref]

12. Zager RA (1989) Studies of mechanisms and protective maneuvers in myoglobinuric acute renal injury. Lab Invest 60: 619-629. [crossref]

13. Brown J, Mitchell S (1992) A complicated case of exertional heat stroke in a military setting with persistent elevation of creatine phosphokinase. Mil Med 157: 101-103. [crossref]

14. Sato K1, Yoneda M, Hayashi K, Nakagawa H, Higuchi I et al. (2006) A steroidresponsive case of severe rhabdomyolysis associated with cytomegalovirus infection. Rinsho Shinkeigaku 46: 312-316. [crossref]

15. Zarlasht F, Salehi M, Sattar A, Abu-Hishmeh M, Khan M (2017) Short-Term HighDose Steroid Therapy in a Case of Rhabdomyolysis Refractory to Intravenous Fluids. Am J Case Rep 18: 1110-1113. [crossref]

16. Yasumoto N, Hara M, Kitamoto Y, Nakayama M, Sato T (1992) Cytomegalovirus infection associated with acute pancreatitis, rhabdomyolysis and renal failure. Intern Med 31: 426-430. [crossref]

17. Melli G, Chaudhry V, Cornblath DR (2005) Rhabdomyolysis: an evaluation of 475 hospitalized patients. Medicine (Baltimore) 84: 377-385. [crossref]

18. Keltz E, Khan FY, Mann G (2014) Rhabdomyolysis. The role of diagnostic and prognostic factors. Muscles Ligaments Tendons J 3: 303-312. [crossref]

\section{Citation:}

Shivam Krishna Patel, Azeem Mohammed, Rajan Kapoor (2019) Role of Corticosteroids in Rhabdomyolysis. Integr J Nephro Urol Stud Volume 1(1): 1-4. 